\title{
Commentary: Pay me now or pay me later: Acute aortic dissection concomitant with a giant abdominal aortic aneurysm
}

\author{
Vicente Orozco-Sevilla, MD, and Tomas A. Salerno, MD
}

\footnotetext{
From the Division of Cardiothoracic Surgery, University of Miami Miller School of Medicine and Jackson Memorial Hospital, Miami, Fla.

Disclosures: Authors have nothing to disclose with regard to commercial support.

Received for publication Feb 12, 2019; accepted for publication Feb 12, 2019; available ahead of print March 20, 2019.

Address for reprints: Vicente Orozco-Sevilla, MD, Division of Cardiothoracic Surgery, University of Miami Miller School of Medicine and Jackson Memorial Hospital, Holtz Center, 1611 N.W. 12 Ave, Room 3072, Miami, FL 33136 (E-mail: vxo78@miami.edu).

J Thorac Cardiovasc Surg 2019;158:e163

$0022-5223 / \$ 36.00$

Copyright (C) 2019 by The American Association for Thoracic Surgery

https://doi.org/10.1016/j.jtcvs.2019.02.063
}

The slogan "you can pay me now or you can pay me later" was used during a marketing campaign from a company that manufactured oil filters. It meant that you can pay little for an oil change and a new filter, or pay a lot later for an engine rebuild. The slogan still applies for many of the procedures that cardiovascular surgeons do or don't. In this current issue of the Journal, $\mathrm{Xu}$ and colleagues ${ }^{1}$ describe the concomitant treatment of a patient with an acute type A aortic dissection and a giant abdominal aortic aneurysm. The authors are to be commended for their surgical skills and resolution of this rather complex problem. Reasons why a 24-year-old patient was stented at this early age remain unclear. Also, the reasons for lack of careful follow-up by the team who performed the first procedure is not explained.

Stents have been used in the treatment of complex type B aortic dissection in an effort to improve true-lumen perfusion and diameter, to increase aortic event-free survival, and to decrease reinterventions without increasing short-term mortality. Important questions remain to be answered in relation to changes in arterial stiffness after aortic endo-grafting, and the relation to future cardiovascular complications, as described by the elegant study by Tzilalis and colleagues. ${ }^{2}$ In this study, 11 young patients were treated with thoracic endovascular aortic repair for aortic transections and developed associated increments in pulse-wave velocities and persistent hypertension. It is possible that implantation of a stent stimulates an inflammatory response, ${ }^{3}$ and this could explain the alterations in elastic properties of the aorta that may be related to late complications associated with endovascular repairs. This is similar to dissection and

\section{References}

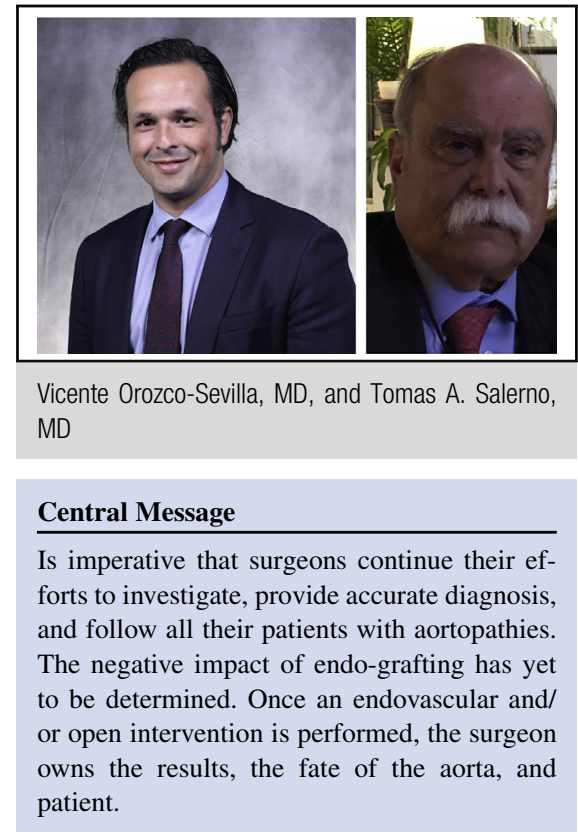

See Article page e161.

aneurysm formation in unstented aorta. All of these questions are difficult to answer with a single case report. However, it is hoped that this will trigger discussions regarding the negative impact of endo-grafting on mechanics of the aorta. It will also generate awareness of the importance of close surveillance of patients who have treatments of aortopathies. As surgeons, we own the fate of the aorta and the patient.

1. Xu S, Sun L, Zhang H. Acute aortic dissection with a concomitant giant abdomina aorta aneurysm. J Thorac Cardiovasc Surg. 2019;158:e161-2.

2. Tzilalis VD, Kamvysis D, Panagou P, Kaskarelis I, Lazarides MK, Perdikides T, et al. Increased pulse wave velocity and arterial hypertension in young patients with thoracic aortic endografts. Ann Vasc Surg. 2012;26:462-7.

3. Arnaoutoglou E, Kouvelos G, Milionis H, Mavridis A, Kolaitis N, Papa N Post-implantation syndrome following endovascular abdominal aortic aneurysm repair: preliminary data. Interact Cardiovasc Thorac Surg. 2011;12:609-14. 